\title{
Normalized tornado damage in the United States: 1950-2011
}

\author{
Kevin M. Simmons ${ }^{\mathrm{a}}$, Daniel Sutter ${ }^{\mathrm{b}}$ and Roger Pielke ${ }^{\mathrm{c} *}$ \\ ${ }^{a}$ Department of Economics and Business Administration, Austin College, Sherman, TX, 75090, USA; \\ ${ }^{b}$ Sorrell College of Business, Troy University, Troy, AL 36082, USA; ${ }^{c}$ Environmental Studies Program, \\ University of Colorado, Boulder, CO 80309, USA
}

(Received 19 September 2011; final version received 5 October 2012)

In 2011, thunderstorms in the United States resulted in 550 deaths from tornadoes and more than $\$ 28$ billion in property damage, according to data from the US National Oceanic and Atmospheric Administration, with the vast majority of economic losses resulting from tornadoes. This article normalizes U.S. tornado damage from 1950 to 2011, using several methods. A normalization provides an estimate of the damage that would occur if past events occurred under a common base year's societal conditions. We normalize for changes in inflation and wealth at the national level and changes in population, income and housing units at the county level. Under several methods, there has been a sharp decline in tornado damage. This decline corresponds with a decline in the reported frequency of the most intense (and thus most damaging) tornadoes since 1950. However, quantification of trends in tornado incidence is made difficult due to discontinuities in the reporting of events over time. The normalized damage results are suggestive that some part of this decline may reflect actual changes in tornado incidence, beyond changes in reporting practices. In historical context, 2011 stands out as one of the most damaging years of the past 61 years and provides an indication that maximum damage levels have the potential to increase should societal change lead to increasing exposure of wealth and property.

Keywords: tornado; damage; normalization; economics; United States

\section{Introduction}

According to statistics compiled by the US National Oceanic and Atmospheric Administration, with 550 deaths in 2011, tornadoes in the United States resulted in the greatest loss of life since the 1920s. NOAA estimated property damage from thunderstorms at about $\$ 28$ billion (which includes hail, straight-line winds and tornadoes), far surpassing previous loss totals. However, because society is undergoing constant change - typically in the direction of greater accumulation and concentration of wealth - it can be very difficult and potentially misleading to interpret such losses in historical context by simply comparing loss totals over time. In this article we present the first comprehensive analysis of US tornado damage in which losses are normalized to a common base year, allowing for a more rigorous evaluation of loss trends and magnitude in historical context.

Unlike hurricanes, floods and earthquakes in the United States, until now no study has systematically analysed the historical record of tornado losses using methodologies of normalization. The magnitude of the task of systematically analyzing tornado losses is large - from 1950 to

\footnotetext{
*Corresponding author. Email: pielke@colorado.edu
} 
2011 records kept by the US National Oceanic and Atmospheric Administration document 56,457 tornado events, of which 33,756 resulted in reported damage. Brooks and Doswell (2001) have applied normalization methodologies to tornadoes, looking at several significant events from 1890 to 1999 , but did not normalize events comprehensively over time. Boruff et al. (2003) looked at trends in tornado incidence and damage comprehensively from 1950 to 2000 , but did not apply normalization methods to the losses. Here, we build on this earlier work by presenting the first comprehensive normalization of US tornado losses for 1950 to 2011 .

This paper proceeds in five parts. First, we discuss the data used in the analysis. Second, we provide an overview of the normalization methodologies. Third, we present the results of the analysis and explore several consistency checks, including a discussion on trends and reporting in tornado incidence. Fourth, the paper explores the relationship of trends in damage with trends in the reported incidence of tornadoes. The paper concludes with a discussion on the findings in broader historical, scientific and policy contexts.

\section{Damage data}

The research conducted here uses a tornado event archive maintained by the US government's Storm Prediction Center (SPC), a department of NOAA, which has been analysed by Simmons and Sutter (2011). Economic damage is defined as the direct economic losses associated with a tornado's impact, as determined in the weeks and sometimes months after the event, and includes the direct property damage and crop losses (if any) related to the event. Indirect damage, including longer-term macroeconomic effects and the economics associated with the valuation of human life, are not considered in this analysis.

The SPC damage archive has long-vexed researchers due to its uneven quality from event to event and lack of completeness. Storm reports are filed by each National Weather Service office and are closed after 60 days. This means that some events may not be recorded or damage totals may not reflect the final loss totals compiled by other sources, which may take more than 60 days to fully tabulate. At the same time there is valuable information in the storm data record.

For instance, 1953, 1965, 1974 and 2011 each stand out as large loss years - even without normalizing the data to a common base year, and each of these years saw major tornado outbreaks with large damage. ${ }^{1}$

1953: During 1953, 519 people died and over 5000 were injured. Three tornadoes killed a total of 320 people in Waco, TX, Flint, MI and Worcester, MA during May and June of that year. In all 407 of the 519 fatalities occurred in three major outbreaks during those months. Also, \$360 of the \$494 million (in current year) damage occurred during those months as well. The outbreak in May stretched across 3 days from May 9 through May 11 and affected states from Texas across the Midwest to South Dakota. In June, two major outbreaks occurred, one in the upper Midwest that also claimed 116 lives in Flint, MI. Another outbreak ripped through the northeast and claimed 90 lives in Worcester, MA. This tornado also caused $\$ 275$ million in damages making it the largest single storm damage total since records began being kept in 1950 .

1965: This year is noted for another tragic year of tornadoes but most notably the fact that most of the casualties and damage occurred on one day, April 11, Palm Sunday. In all 301 people were killed, 260 of those on April 11. Also, of the $\$ 1.1$ billion in (current year) damage, $\$ 744$ million occurred on that day. The tornadoes stretched from Wisconsin to Ohio. Unlike 1953, there was not any one storm that killed more than 100 people but there were 10 tornadoes that each killed more than 10 in Indiana, Michigan and Ohio. 
1974: Like the 1965 Palm Sunday outbreak, the largest outbreak in 1974 occurred on one day, Wednesday, April 3. For 1974 in total, 348 people died and over 6500 suffered injuries, with $\$ 1.5$ billion (current year) in damage. April 3 accounted for 290 of the fatalities, 5100 of the injuries and $\$ 1.2$ billion of the damage. The day was termed as the 'Super Outbreak' because it not only did so much damage and caused so many casualties but it also stretched from the Upper Midwest across the Ohio Valley, as far north as New York and as far south as Mississippi.

2011: In many ways, the tornadoes of 2011 most resemble what happened in 1953. Unlike 1965 and 1974, there was not one day or even one outbreak that caused such a large percentage of the damage. Two outbreaks stand out, late April in the southeast most notably Alabama on April 27 where one tornado remained on the ground from Tuscaloosa to the suburbs of Birmingham, a total of over 100 miles. And on May 22, an EF-5 tornado tragically struck Joplin, MO killing 151 people (Smith, 2012). This tornado was rated EF-5 for 6 of its 21-mile life but those 6 miles were in the middle of a heavily populated area. About 7000 homes were destroyed and estimates from this tornado alone approach $\$ 3$ billion.

To extract value from the SPC dataset, we apply a new methodology made possible by the unique characteristics of the dataset. The SPC dataset uses a consistent approach to damage data collection, which means that damage has been recorded by a single government agency over time using a common methodology. Such a dataset enables the application of a meaningful normalization methodology in the context of uncertainties in damage estimates (Downton \& Pielke, 2005; Downton, Miller, \& Pielke, 2005; Pielke et al., 2008; Vranes \& Pielke, 2009). The methodology is described in detail below.

From 1950 to 1995, the SPC recorded damage estimates for individual tornadoes within one of nine intervals, which collectively span the range from $\$ 0$ to $\$ 5$ billion. Most tornadoes cause little or no damage. Of the more than 35,000 tornadoes documented from 1950-1995, 28\% or over 10,000 had a damage interval of 0 , indicating that the damage was either zero or unknown. Damage from the remaining tornadoes form something close to a normal distribution around a modal point where the damage interval equals 4 . The highest category of the binned data, used from 1950 to 1995 and representing damage greater than $\$ 500$ million (current year dollars), was never used by SPC. The next highest interval, with a damage of $\$ 50$ to $\$ 500$ million, includes only 29 total events $(0.05 \%$ of the total).

Table 1 shows the damage intervals.

Beginning in 1996 a specific damage estimate has been provided for each event with the loss given as an integer in millions of dollars. In 2008 and subsequent years, this loss amount was broken into two components, monetary loss and crop loss. For 2008-2011, we use the sum of monetary and crop loss, for consistency with pre-2008 data.

Table 1. SPC damage intervals used from 1950 to 2011.

\begin{tabular}{ll}
\hline 0 & Zero damage or unknown \\
1 & Less than $\$ 50$ \\
2 & $\$ 50-\$ 500$ \\
3 & $\$ 500-\$ 5000$ \\
4 & $\$ 5000-\$ 50,000$ \\
5 & $\$ 50,000-\$ 500,000$ \\
6 & $\$ 500,000-\$ 5,000,000$ \\
7 & $\$ 5,000,000-\$ 50,000,000$ \\
8 & $\$ 50,000,000-\$ 500,000,000$ \\
9 & $\$ 500,000,000-\$ 5,000,000,000$ \\
\hline
\end{tabular}


The more precise data from 1996 to 2011 allow us to calculate the statistical properties of the losses within each of the nine bins that were applied in the earlier period. Since we know how many events occurred within each bin from 1950 to 1995, we assign a value to each pre-1996 event based on the distribution of events observed during the more recent period. This approach will not have much accuracy for any single event, but given the large number of events that occur in a year, in general it will allow a more accurate approach to calculating total annual losses than non-empirical approaches, e.g., such as taking the mid-point of the bins or applying an arbitrary function (e.g. such as exponential decay).

Specifically we followed the following procedure:

(1) Assigned 1996-2011 loss events to 1950-1995 bins using current dollar damage values

(2) Within bins then inflated damage values to 2011 dollars, using the Consumer Price Index (as described in the following section)

(3) Calculated summary statistics for each bin

(4) Applied the mean event loss for each bin to 1950-1995 events

(5) Summed by year to arrive at 2011 inflation-adjusted losses

The summary statistics associated with the 1996 to 2011 losses are shown in Table 2.

To test the fidelity of this damage assignment procedure, we compared the statistics of the bins in the two periods in terms of normalized losses per bin and normalized loss per tornado. ${ }^{2}$ As the normalization process is designed to allow for an apple-to-apple comparison of losses across years, the statistics between the two periods is expected to be similar in the absence of a bias. For the period 1950 to $1995,99.9 \%$ of total normalized damage was reported in bins 5-9, and for the period 1996 to 2011 bins 5-9 contained $99.8 \%$ of damage. ${ }^{3}$ The average difference in normalized losses per tornado between the two time periods and across these five bins is 5\% per bin. Across the three bins 7-9 which account for about 90\% of total normalized damage for each of the two periods, the average difference in normalized losses per tornado between the two time periods and across these five bins is less than $1 \%$ per bin. ${ }^{4}$ As the loss estimates per tornado per bin are undoubtedly uncertain to a magnitude greater than $1 \%$ or $5 \%$, this test provides strong evidence to support the fidelity of our methodology for ascribing specific loss estimates to the period 1950-1995 when tornado losses were binned based on the statistical properties of losses 1996-2011, the period in which a specific loss estimate was assigned to each event. This test of the damage assignment methodology clearly does not introduce a detectable bias into the results.

With a complete set of loss estimates generated and tested using the procedures above, we next create index of losses from 1950 to 2010, which through 2010 is shown in Figure 1.

Table 2. Summary statistics of 1996-2011 loss events segregated by 1950-1995 bins

\begin{tabular}{lccccccc}
\hline Bin & $N$ & Mid-point & Median & Mean & Min & Max & SD \\
\hline 2 & 43 & 0.000275 & 0.0005 & 0.0005 & 0.0001 & 0.0007 & 0.0002 \\
3 & 894 & 0.00275 & 0.002 & 0.0030 & 0.0008 & 0.0058 & 0.0017 \\
4 & 3106 & 0.0275 & 0.02 & 0.0276 & 0.0060 & 0.0656 & 0.0168 \\
5 & 2709 & 0.275 & 0.15 & 0.2198 & 0.0537 & 0.6560 & 0.1503 \\
6 & 1371 & 2.75 & 1 & 1.9835 & 0.5010 & 7.1990 & 1.3727 \\
7 & 349 & 27.5 & 12 & 18.5979 & 5.0100 & 69.3006 & 13.7500 \\
8 & 73 & 275 & 100 & 144.2539 & 53.4050 & 454.2957 & 92.0428 \\
9 & 8 & 750 & 1000 & 1339.4900 & 501.0000 & 2800.1000 & 801.1549 \\
\hline
\end{tabular}

There were 8553 total events from 1996 to 2011. 


\section{Index of 1950-2010 Tornado Losses: \\ Annual Average $=\mathbf{1 . 0}$}

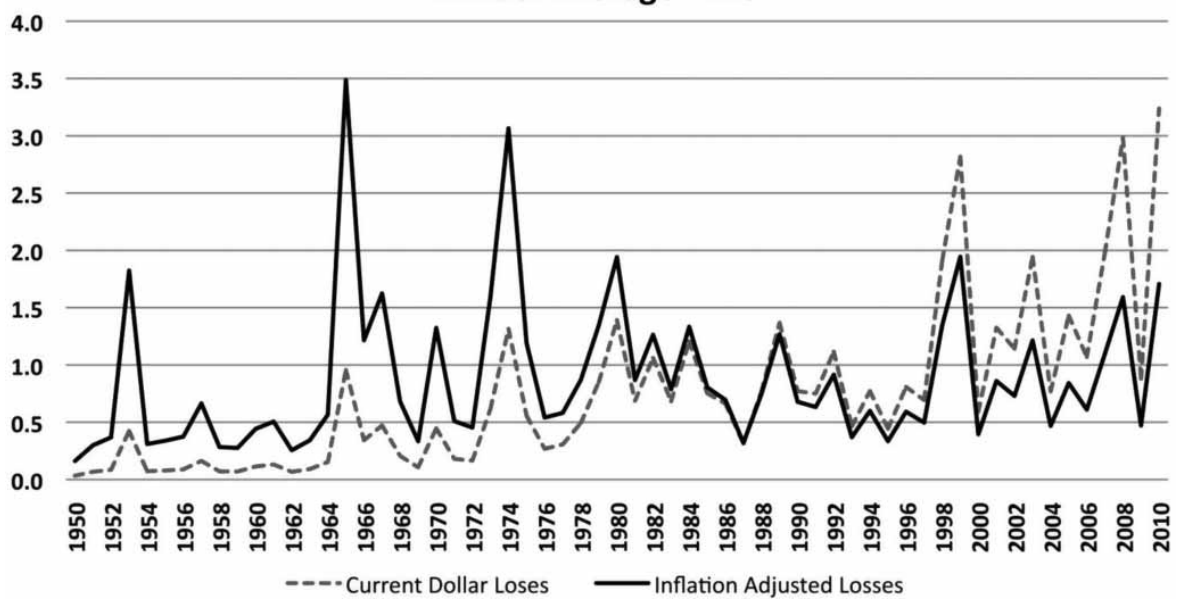

Figure 1. An index of tornado losses in the SPC database, 1950-2011. The dashed line shows current dollar losses and the solid line shows losses adjusted for inflation.

We initially present an index, rather than the dollar-loss estimated because of concerns over the completeness of the loss record in the SPC dataset, specifically, while there is no evidence of systematic bias over time, there is concern that the losses from the SPC archive underestimate losses as compared with other sources. ${ }^{5}$ However, we return to the issue of dollar-loss estimates in a subsequent section of this article. The losses for 2011 are, literally, off the chart, with the currentdollar values more than 16 times the long-term average and the inflation-adjusted values more than 8 times the long-term average.

As a starting point, we assume that uncertainties that result from errors in original reporting, the binning process used through 1995 and other factors are randomly distributed over more than 33,000 events with reported damage. The presence of systematic biases in the dataset would affect the results of our analysis. We believe it more likely that such a bias, were it to exist, would more likely manifest itself as an under-reporting of damage, rather than an over-reporting, due to the nature of the SPC data collection procedures. In the results presented below, we perform a consistency check on the results by comparing trends in tornado incidence with trends in damage to explore the possibility of a systematic bias. We find no such evidence of a systemic bias in the results.

The greatest recorded loss in the SPC database from a single tornado event prior to 2011 was a loss of $\$ 1$ billion (current) in the 3 May 1999 tornado that hit the densely populated Oklahoma City metro area. The storm was rated an F-5 on the Fujita scale and killed dozens of people. The Fujita (F) Scale was developed in 1971 to rate tornado intensity based on observed damage and has six categories, F0 to F5. It was updated in 2007 and is now referred to as the Enhanced Fujita (EF) Scale. Throughout this article we use the F-scale for events prior to 2008 and the EF-scale for events 2009-2011; however, our nomenclature uses the earlier terminology for simplicity. The difference between the two scales has no bearing on our analysis. However, several analyses have suggested the presence of discontinuities in the application of the F-scale during different historical periods, which we address in the analysis below.

The amount of damage that a tornado will create is highly dependent on the size of the tornado with most of the damage coming from tornadoes rated F-3 or higher $(68 \%$ of total 
damage, 1950-2011 in the raw F-scale data). Individual event loss estimates come with considerable uncertainty (e.g. in a study of flood losses greater than $\$ 500$ million as recorded by NOAA; Downton and Pielke (2005) found independent loss estimates varied by as much as $40 \%$ ), but the annual totals on which we focus involve less uncertainty because of the very large number of events and will reduce the uncertainty in the annual totals, at least under the methodology applied by the SPC.

The values underlying the index calculated here serve as the input to the application of three methodologies of normalization.

\section{Methodology}

A normalization analysis begins by asking a deceptively simple question: what damage would result if extreme events of the past occurred under the societal conditions of 2011?

To answer this question, we employ a methodology of loss normalization that has been well developed over the past 15 years and applied to economic losses for events as diverse as US hurricanes and earthquakes, European floods and windstorms, tropical cyclones in India and China, and Australian extreme weather events. Bouwer (2011) provides a recent review of this literature. In general, a normalization seeks to adjust actual damages in a given year to a common base year, with the goal of removing the signal of societal change in the data.

A first adjustment is for changes in inflation, i.e. the decrease in value of a currency over time, and we use the Consumer Price Index from the Bureau of Labor Statistics to adjust all data to 2011 dollars (U.S. Department of Labor, 2011). Following the inflation adjustment, we employ several different approaches to normalization using independent datasets: (a) Gross Domestic Product as a measure of national wealth (U.S. Department of Commerce, 2011) and (b) US population at the county level combined with (b1) housing units and (b2) household income at the county level. We thus present results from three approaches to normalization.

The basic form of a normalization uses base year economic damage (i.e. the index that was presented in the previous section), and applies as relevant, inflation, population, wealth (or housing unit) multipliers, to generate the 2011 annual normalized damage estimate, as follows:

$$
D_{2011}=\sum D_{y i} \times I_{y} \times \mathrm{WPC}_{y i} \times P_{y i}
$$

where

$D_{2011}$ : annual normalized damages in 2011 dollars

$D_{y i}$ : reported damages per event $i$ in current-year dollars

$I_{y}$ : inflation adjustment for year $y$

$\mathrm{WPC}_{y}$ : real wealth per capita adjustment for event $i$ in year $y$

$P_{y i}$ : population adjustment for event $i$ in year $y$.

Events $i$ to $n$ are summed over the year to generate an annual loss total.

The simplest approach to normalization adjusts historical losses for GDP, which includes changes at the national level in income and population. A GDP-based normalization in the context of hurricanes has been shown to closely finer-grained methods based on population, wealth and housing units for losses since 1950, but is much less accurate further back in time (cf. Nordhaus, 2010; Pielke, 2008). A normalization using GDP may be less accurate for tornadoes because GDP is a national metric and while tornadoes occur across the country, damage is concentrated in a subset of states, which may or may not follow national patterns of change in GDP over different periods of time.

Thus, in the results shown below, in addition to a GDP-based normalization, we also employ two finer-grained methods, both following from the methodology used in Pielke et al. (2008) for 
normalizing US hurricane damage. The first fine-grained method adjusts historical losses for changes in population and wealth for only those counties affected by tornado losses. The second fine-grained method adjusts for changes in housing units and wealth for only those counties affected by tornado losses.

\section{Normalization results}

Figure 2 shows the results of the three different approaches to normalization: the GDP-based normalization, county population and county income-based normalization, and the county population and county (1970-2010)/national (1950-1969) housing unit-based normalization. Because housing unit data are available only from 1970, we use national housing unit data as a proxy from 1950 to 1969 . A comparison of the national housing unit data to the county-level data for the period 1970-2010 indicates that national housing unit data slightly underestimate the results from application of the county-level housing unit data, suggesting that the national data are an appropriate proxy back to 1950, and may slightly underestimate normalized losses, if the relationship between the data observed for 1970-2011 also holds for 1950-1969 (Figure 2).

The results are quite similar across the three methods. A linear trend fit to each of the three series indicates that normalized damage decreased by $35-63 \%$ from 1950 to 2011 , depending on the series (the Population-Income adjustment had the smaller decrease which is not statistically significant, while GDP and Housing Units-Income resulted in the larger increase, significant at $<0.05$ ).

In order to present a dollar-based normalization estimate, we have used 2011 loss estimates from NCDC as a baseline (NOAA, 2011), under the assumption that the most recent year's losses will be the most accurate under the methodology used by NOAA. ${ }^{6}$ NCDC compiled a total loss estimate for all thunderstorm losses based on data from Property Claims Services (a private company that compiles damage for the insurance industry), US flood and crop insurance and Federal Emergency Management Agency payouts (NCDC; A. Smith, personal communication April 26, 2012).

Index of Normalized Tornado Losses: 1950-2011:

Annual Average $=\mathbf{1 . 0}$

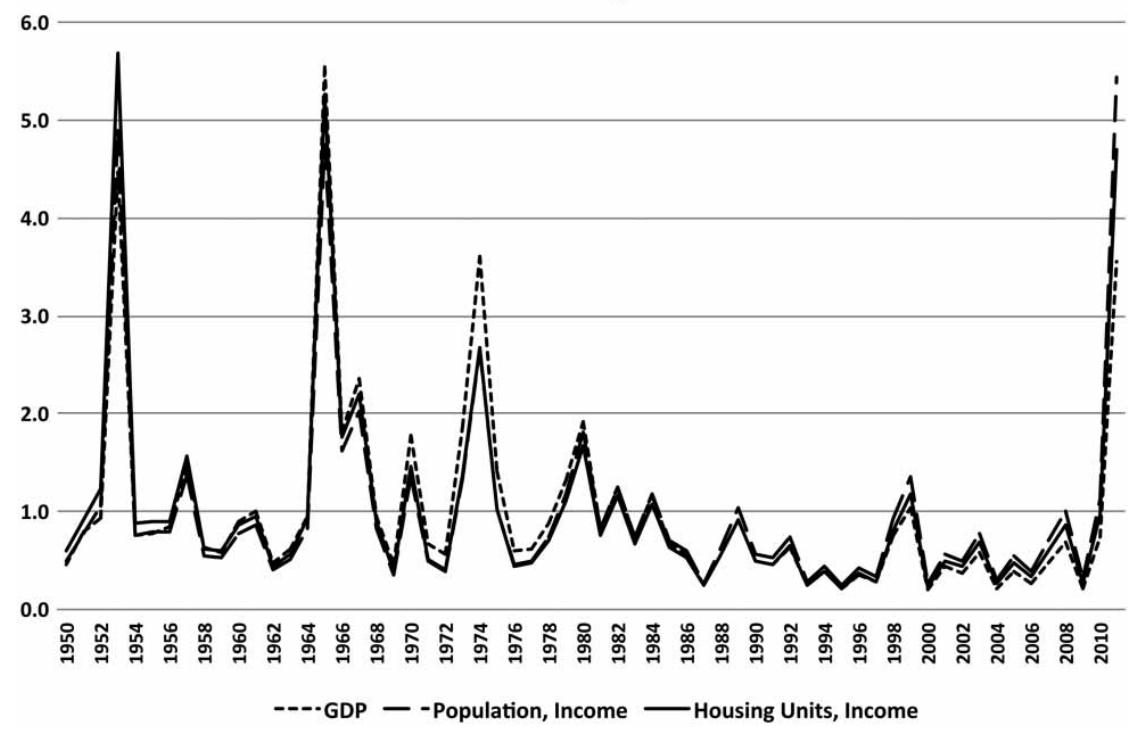

Figure 2. Normalized damage $1950-2011$ as a proportion of the 1950-2011 average annual loss. 
We adjust the estimated $\$ 28$ billion in total thunderstorm losses calculated by NCDC to a tornadoonly estimate by the ratio of tornado losses to total thunderstorm losses in the SPC database, which is 0.92 for 2011. We then calculate estimated losses for the period from 1950 to 2010 for each of the normalization methodologies by scaling them to the 2011 loss estimate.

Figure 3 shows the results of this calculation for each of the three methodologies scaled to the 2011 NCDC loss estimate for $2011 .^{7}$ The scaling of past losses to the 2011 NCDC damage estimate provides an estimate of damages from past events have been under current societal conditions and aggregated using the damage estimation methodology employed by NCDC in 2011. Obviously, normalized damage could be scaled to other estimates.

As expected, the four largest loss years are 1953, 1965, 1974 and 2011. Uncertainties in the data and across methods do not allow a precise ranking of these years as they are very close to one another, but 1974 trails across the approaches and all four years well exceed others over the time period. Of note in the data is the 26-year period from 1974 to 2011 with no losses that exceed $\$ 10$ billion in normalized losses in two of three methods (1980 exceed $\$ 10$ billion using GDP). In contrast, in the first 25 years of the data, normalized losses exceeded $\$ 10$ billion from three to seven times, depending on the normalization methodology.

The three normalization methods result in total losses of $\$ 293$ billion (population and income), \$339 billion (housing unit and income) and \$449 billion (GDP) from 1950 to 2011. Over the same time period, hurricanes result in $\$ 621$ billion in normalized losses over 153 events (Pielke et al., 2008). The 2005 hurricane season alone resulted in $\$ 130$ billion in normalized damage, or more than $38 \%$ of 1950 to 2011 normalized tornado losses using the housing and income normalization method. In contrast, the normalized tornado losses are two to three times the highest estimates of normalized earthquake damage over 1950-2011 (at about \$150 billion) based on Vranes and Pielke (2009). ${ }^{8}$

\section{Trends in losses and tornado incidence}

Each of the three normalization methods (and the underlying index) shows a long-term decline in losses, despite the catastrophic damage of 2011. The GDP and housing unit and income approaches both indicate about a 63\% decline in damages $(P<0.5)$, which the population and income indicates about a $35 \%$ decline (not statistically significant). Does this long-term decline relate to a decreasing incidence of damaging tornadoes?

It turns out that this question is not easy to answer due to recognized discontinuities in the historical record of tornado intensity (see, e.g. Brooks \& Doswell, 2001; Brooks \& Dotzek, 2008; Doswell, Brooks, \& Dotzek, 2008; Feuerstein, Dotzek, \& Grieser, 2005; Verbout, Brooks, Leslie, \& Schultz, 2006). Doswell et al. (2008) summarize their judgement on the fidelity of the intensity ratings as follows:

a period of relatively consistent ratings into the early 1970s, followed by a period of inconsistent practices in the time near the adoption of the F-scale that persisted into the 1990s, followed by a decade of relatively consistent standards through the end of the 20th century.

In particular, the period prior to 1974 shows a larger number of higher category tornadoes due, at least in part, to changes in the methods of reporting as compared with the subsequent period (Verbout et al., 2006). After 1999, the ratings abruptly shifted downward (NOAA/NSSL, H. Brooks, personal communication, April 12, 2012; cf. Doswell et al., 2008). It is widely understood that the large increase in F0 tornadoes is the result of improved reporting, including the advent of Doppler radar systems. As F0 tornadoes result in minimal damage, that increase, while notable, is not germane to this study. 
(a)

Normalized Tornado Losses 1950-2011:

GDP Method

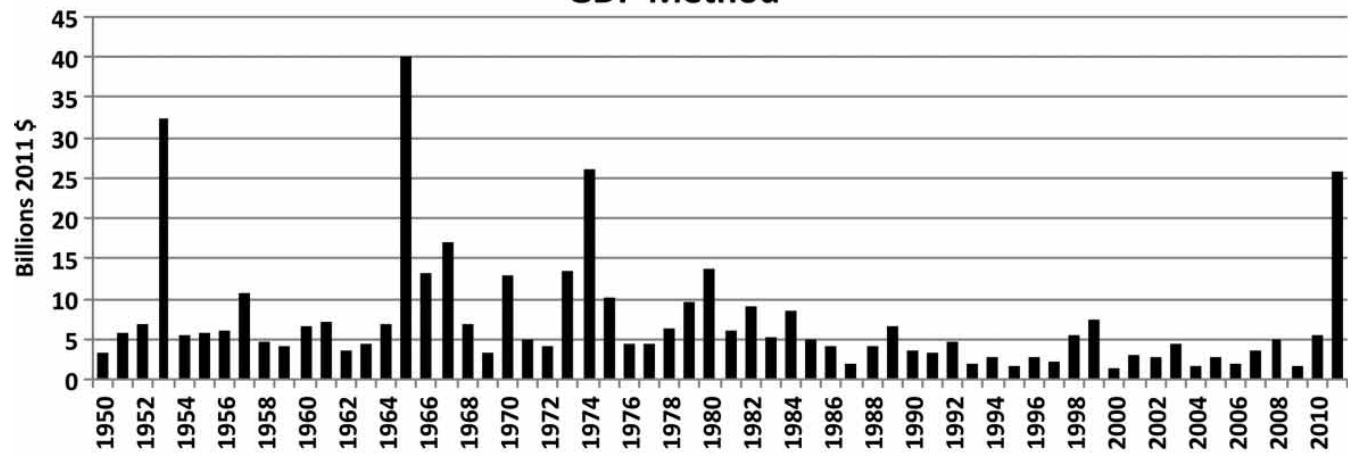

(b)

Normalized Tornado Losses 1950-2011:

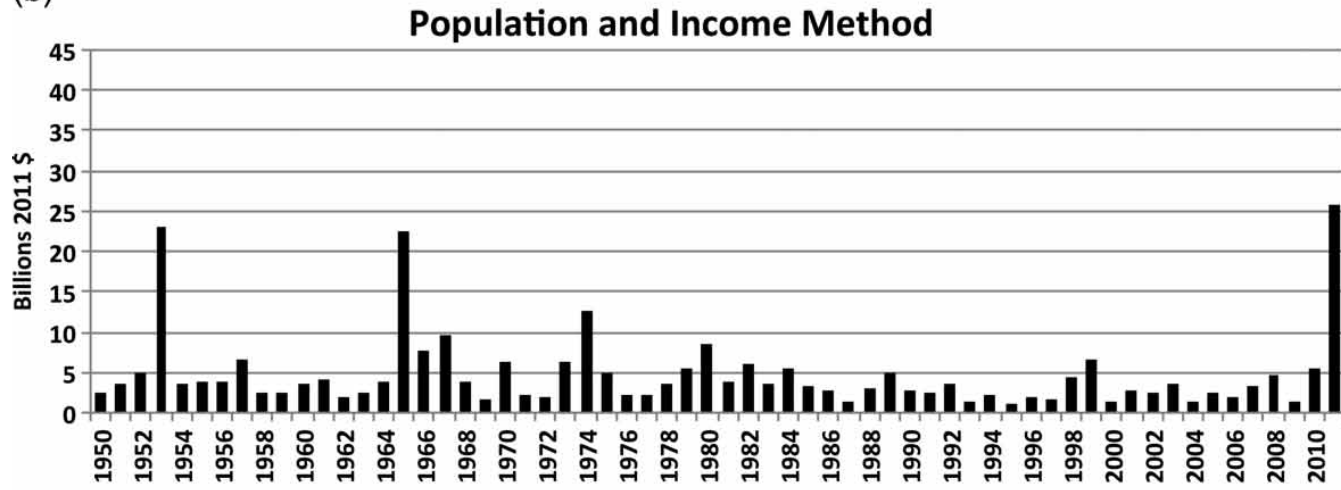

(c)

Normalized Tornado Losses 1950-2011:

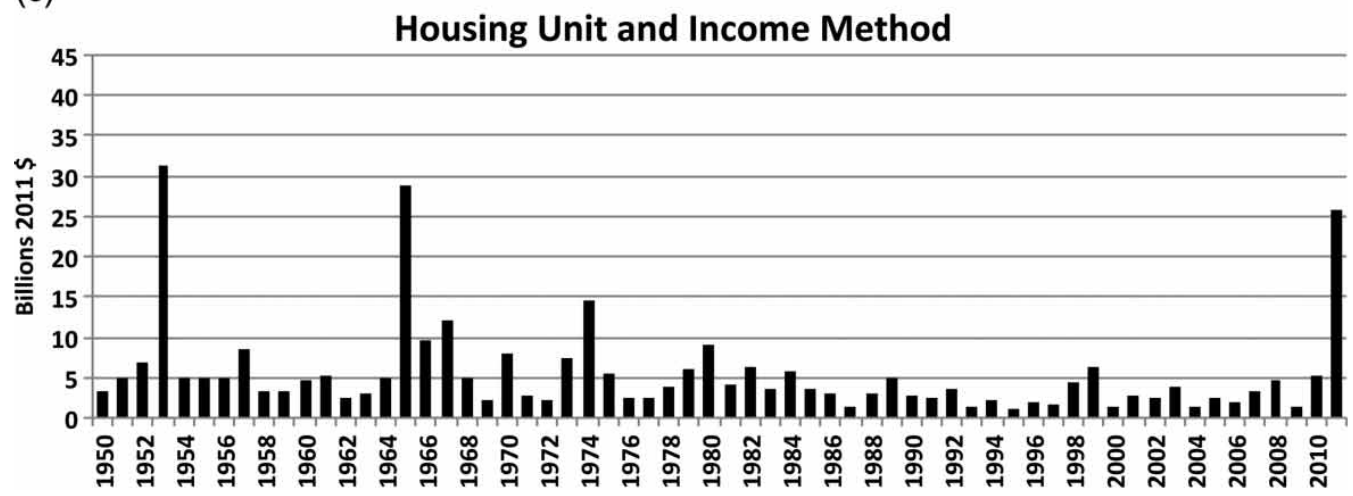

Figure 3. Normalized US tornado damage 1950-2011 scaled to the 2011 NCDC annual loss estimate, (a) normalized by national GDP, (b) normalized by county population and income and (c) normalized by county housing unit and income (1970-2010) and national housing unit and county income (1950-2010).

To minimize the effects of changes in reporting and explore the possibility of secular changes in tornado incidence as a factor in the decreased losses, we explore damage by intensity category in three subset periods of the overall database: 1950-1973, 1974-1999 and 2000-2011. The summary statistics, along with data for the entire period, are shown in Table 3. 
Table 3. Damage by F-Scale category for four different periods, 1950 to 2011, 1950 to 1973, 1974 to 1999 and 2000 to 2011.

\begin{tabular}{|c|c|c|c|c|c|c|c|c|c|c|c|c|c|}
\hline $1950-2011$ & F-Scale & Tornadoes & $\begin{array}{l}\text { Percent } \\
\text { of total }\end{array}$ & $\begin{array}{l}\text { Damage } \\
\text { current } \\
\text { (in dollars) }\end{array}$ & $\begin{array}{l}\text { Percent } \\
\text { of total }\end{array}$ & $\begin{array}{c}\text { Damage CPI } \\
\text { Adj } \\
\text { (in dollars) }\end{array}$ & $\begin{array}{l}\text { Percent } \\
\text { of total }\end{array}$ & $\begin{array}{l}\text { Damage } \\
\text { GDP norm } \\
\text { (in dollars) }\end{array}$ & $\begin{array}{l}\text { Percent } \\
\text { of total }\end{array}$ & $\begin{array}{c}\text { Damage Pop } \\
\text { norm } \\
\text { (in dollars) }\end{array}$ & $\begin{array}{l}\text { Percent } \\
\text { of total }\end{array}$ & $\begin{array}{l}\text { Damage } \\
\text { house norm } \\
\text { (in dollars) }\end{array}$ & $\begin{array}{l}\text { Percent } \\
\text { of total }\end{array}$ \\
\hline & 0 & 26,377 & 47 & 643 & 1 & 1292 & 2 & 2854 & 1 & 1831 & 1 & 2069 & 1 \\
\hline & 1 & 18,326 & 32 & 5852 & 13 & 9863 & 12 & 19,123 & 10 & 13,108 & 10 & 14,494 & 10 \\
\hline & 2 & 8688 & 15 & 7571 & 17 & 16,759 & 20 & 40,930 & 21 & 25,842 & 20 & 30,039 & 20 \\
\hline & 3 & 2391 & 4 & 9793 & 23 & 20,444 & 24 & 48,763 & 25 & 31,319 & 24 & 36,235 & 24 \\
\hline & 4 & 601 & 1 & 11,402 & 26 & 23,766 & 28 & 58,909 & 30 & 38,440 & 30 & 45,307 & 30 \\
\hline & 5 & 74 & 0 & 8173 & 19 & 13,246 & 16 & 27,377 & 14 & 18,810 & 15 & 21,586 & 14 \\
\hline & & 56,457 & & 43,435 & & 85,371 & & 197,956 & & 129,350 & & 149,729 & \\
\hline \multirow[t]{8}{*}{$1950-1973$} & F-Scale & Tornadoes & $\begin{array}{l}\text { Percent } \\
\text { of total }\end{array}$ & $\begin{array}{l}\text { Damage } \\
\text { current } \\
\text { (in dollars) }\end{array}$ & $\begin{array}{l}\text { Percent } \\
\text { of total }\end{array}$ & $\begin{array}{c}\text { Damage CPI } \\
\text { Adj } \\
\text { (in dollars) }\end{array}$ & $\begin{array}{l}\text { Percent } \\
\text { of total }\end{array}$ & $\begin{array}{l}\text { Damage } \\
\text { GDP norm } \\
\text { (in dollars) }\end{array}$ & $\begin{array}{l}\text { Percent } \\
\text { of total }\end{array}$ & $\begin{array}{c}\text { Damage Pop } \\
\text { norm } \\
\text { (in dollars) }\end{array}$ & $\begin{array}{l}\text { Percent } \\
\text { of total }\end{array}$ & $\begin{array}{c}\text { Damage } \\
\text { house norm } \\
\text { (in dollars) }\end{array}$ & $\begin{array}{l}\text { Percent } \\
\text { of total }\end{array}$ \\
\hline & 0 & 4178 & 28 & 41 & 1 & 286 & 1 & 1155 & 1 & 660 & 1 & 850 & 1 \\
\hline & 1 & 5374 & 36 & 249 & 7 & 1656 & 7 & 6519 & 6 & 3735 & 6 & 4808 & 6 \\
\hline & 2 & 4178 & 28 & 917 & 25 & 5993 & 24 & 23,011 & 23 & 13,098 & 22 & 16,803 & 22 \\
\hline & 3 & 1053 & 7 & 833 & 23 & 5721 & 23 & 23,589 & 23 & 13,855 & 23 & 17,968 & 23 \\
\hline & 4 & 266 & 2 & 1073 & 29 & 7808 & 31 & 32,633 & 32 & 19,839 & 33 & 25,854 & 33 \\
\hline & 5 & 34 & 0 & 530 & 15 & 3642 & 15 & 14,235 & 14 & 8463 & 14 & 10,910 & 14 \\
\hline & & 15,083 & & 3643 & & 25,106 & & 101,143 & & 59,650 & & 77,192 & \\
\hline \multirow[t]{8}{*}{ 1974-1999 } & F-Scale & Tornadoes & $\begin{array}{l}\text { Percent } \\
\text { of total }\end{array}$ & $\begin{array}{l}\text { Damage } \\
\text { current } \\
\text { (in dollars) }\end{array}$ & $\begin{array}{l}\text { Percent } \\
\text { of total }\end{array}$ & $\begin{array}{c}\text { Damage CPI } \\
\text { Adj } \\
\text { (in dollars) }\end{array}$ & $\begin{array}{l}\text { Percent } \\
\text { of total }\end{array}$ & $\begin{array}{l}\text { Damage } \\
\text { GDP norm } \\
\text { (in dollars) }\end{array}$ & $\begin{array}{l}\text { Percent } \\
\text { of total }\end{array}$ & $\begin{array}{c}\text { Damage Pop } \\
\text { norm } \\
\text { (in dollars) }\end{array}$ & $\begin{array}{l}\text { Percent } \\
\text { of total }\end{array}$ & $\begin{array}{l}\text { Damage } \\
\text { house norm } \\
\text { (in dollars) }\end{array}$ & $\begin{array}{l}\text { Percent } \\
\text { of total }\end{array}$ \\
\hline & 0 & 12,438 & 49 & 350 & 2 & 726 & 2 & 1405 & 2 & 898 & 2 & 946 & 2 \\
\hline & 1 & 8523 & 34 & 1953 & 12 & 4185 & 12 & 8358 & 12 & 5380 & 12 & 5685 & 12 \\
\hline & 2 & 3207 & 13 & 3511 & 22 & 7283 & 21 & 14,240 & 20 & 9310 & 21 & 9805 & 21 \\
\hline & 3 & 944 & 4 & 4556 & 28 & 9836 & 28 & 20,012 & 28 & 12,642 & 28 & 13,448 & 28 \\
\hline & 4 & 241 & 1 & 3932 & 24 & 9217 & 26 & 19,331 & 27 & 11,899 & 27 & 12,756 & 27 \\
\hline & 5 & 29 & 0 & 1974 & 12 & 3907 & 11 & 7442 & 11 & 4663 & 10 & 4998 & 10 \\
\hline & & 25,382 & & 16,275 & & 35,154 & & 70,788 & & 44,792 & & 47,639 & \\
\hline \multirow[t]{8}{*}{$2000-2011$} & F-Scale & Tornadoes & $\begin{array}{l}\text { Percent } \\
\text { of total }\end{array}$ & $\begin{array}{l}\text { Damage } \\
\text { current } \\
\text { (in dollars) }\end{array}$ & $\begin{array}{l}\text { Percent } \\
\text { of total }\end{array}$ & $\begin{array}{c}\text { Damage CPI } \\
\text { Adj } \\
\text { (in dollars) }\end{array}$ & $\begin{array}{l}\text { Percent } \\
\text { of total }\end{array}$ & $\begin{array}{l}\text { Damage } \\
\text { GDP norm } \\
\text { (in dollars) }\end{array}$ & $\begin{array}{l}\text { Percent } \\
\text { of total }\end{array}$ & $\begin{array}{c}\text { Damage Pop } \\
\text { norm } \\
\text { (in dollars) }\end{array}$ & $\begin{array}{l}\text { Percent } \\
\text { of total }\end{array}$ & $\begin{array}{l}\text { Damage } \\
\text { house norm } \\
\text { (in dollars) }\end{array}$ & $\begin{array}{l}\text { Percent } \\
\text { of total }\end{array}$ \\
\hline & 0 & 9761 & 61 & 252 & 1 & 280 & 1 & 293 & 1 & 273 & 1 & 272 & 1 \\
\hline & 1 & 4429 & 28 & 3651 & 16 & 4023 & 16 & 4246 & 16 & 3994 & 16 & 4001 & 16 \\
\hline & 2 & 1303 & 8 & 3143 & 13 & 3483 & 14 & 3679 & 14 & 3434 & 14 & 3432 & 14 \\
\hline & 3 & 394 & 2 & 4404 & 19 & 4888 & 19 & 5162 & 20 & 4822 & 19 & 4820 & 19 \\
\hline & 4 & 94 & 1 & 6397 & 27 & 6742 & 27 & 6945 & 27 & 6702 & 27 & 6696 & 27 \\
\hline & 5 & 11 & 0 & 5669 & 24 & 5697 & 23 & 5700 & 22 & 5684 & 23 & 5678 & 23 \\
\hline & & 15,992 & & 23,516 & & 25,111 & & 26,025 & & 24,908 & & 24,898 & \\
\hline
\end{tabular}




\section{Distribution of Normalized Losses by F-Scale: Housing and Income Method}

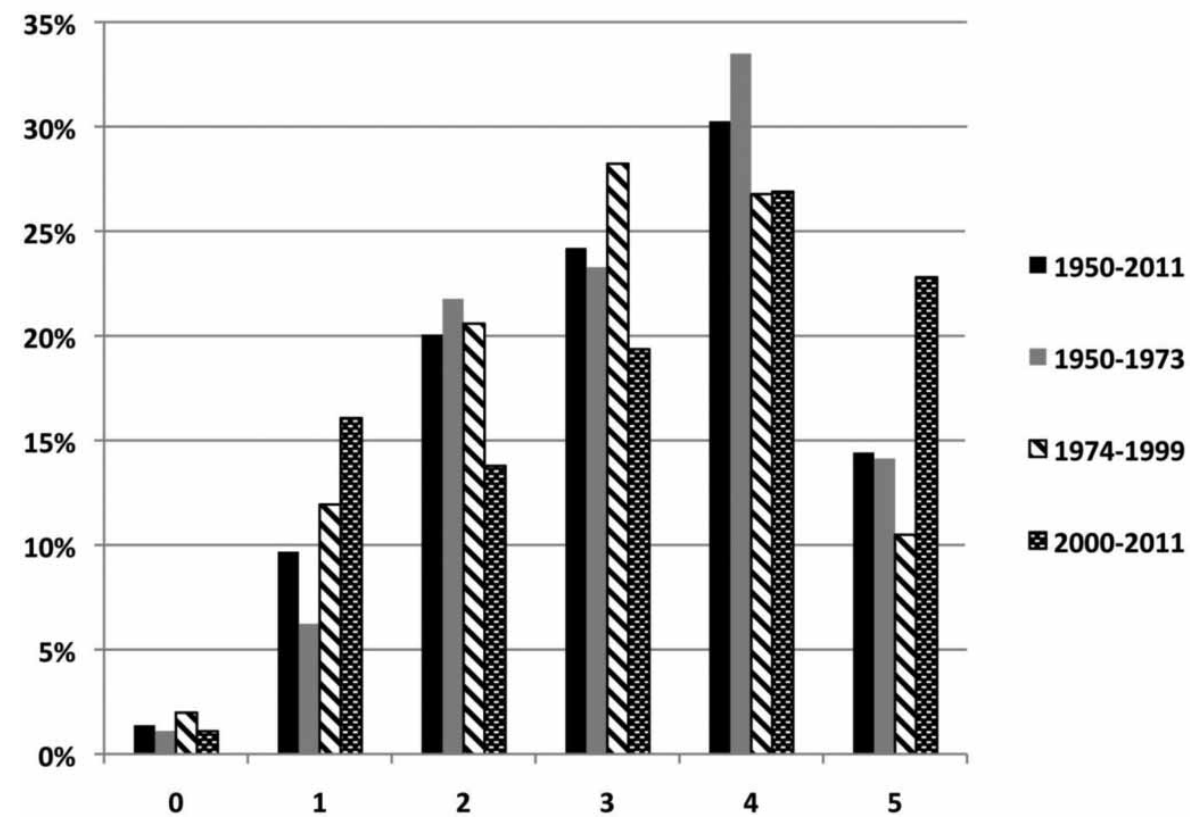

Figure 4. Distribution of normalized losses by F-Scale category for the entire dataset and three sub-periods within that dataset illustrating differences in categorization due to changes in F-scale reporting.

The data show, as expected, a smaller proportion of damage from the most intense tornadoes during 1974-1999 as compared with 1950-1973, and a corresponding larger proportion in the weaker categories. This is consistent with the expectation found in the literature that documents a shift to lower-intensity estimates in the more recent period. The most recent period since 2000 also follows this trend, but because the period is so short, it should be interpreted with caution. Figure 4 shows the distribution of losses by F-category for the three different time periods, as well as for the overall record, illustrated with the housing and income method of normalization (choice of normalization method is not significant here).

The distribution shows a reduction in damage after 1973 in the two strongest categories of tornadoes and a corresponding increase in F3 damage, which is consistent with expectations based on known discontinuities in the database, as described above. For the period 20002011, damage at the highest intensities are dominated by the extreme losses of 2011; however, F2 and F3 losses decrease as a proportion of the total while F1 losses increased, again consistent with expectations based on changes in reporting.

One important consistency check on the methodological fidelity of normalization is to compare trends in the normalized losses with trends in the relevant geophysical phenomena. If normalization has successfully adjusted for the effects of societal change, then the trends in the geophysical or meteorological phenomena should match those in the normalized losses. For instance, there is good confidence in the results of normalizations of hurricane damage because the normalized losses show no trends since 1900, and there are similarly no trends in storm intensity or frequency at landfall (Pielke et al., 2008).

Conducting a similar analysis for tornadoes is not so straightforward, due to the issues associated with discontinuities in reporting practices (cf. IPCC, 2012). While there is a long-term 
Table 4. A comparison of linear trends in tornado incidence and the three methods of normalization for three sub-periods of the overall dataset. Tornado incidence

\begin{tabular}{|c|c|c|c|c|}
\hline & & GDP & Pop & Housing \\
\hline \multicolumn{5}{|l|}{$1950-1973$} \\
\hline Increase*** & F0 & Increase & Increase & Increase \\
\hline Increase ${ }^{* * *}$ & $\mathrm{~F} 1$ & Increase & Increase & Increase \\
\hline Increase*** & $\mathrm{F} 2$ & Increase & Increase & Increase \\
\hline Increase ${ }^{* *}$ & F3 & Decrease & Decrease & Decrease \\
\hline Decrease & F4 & Decrease & Decrease & Decrease \\
\hline Decrease & F5 & Increase* & 1 Decrease ${ }^{* *}$ & Decrease* \\
\hline 1974-1999 & & GDP & Pop & Housing \\
\hline Increase ${ }^{* * *}$ & F0 & Decrease & Decrease & Decrease \\
\hline Decrease & $\mathrm{Fl}$ & Decrease $^{* *}$ & Decrease* $^{*}$ & Decrease* \\
\hline Decrease $^{* * *}$ & F2 & Decrease $^{* *}$ & Decrease & Decrease* \\
\hline Decrease & F3 & Decrease $^{* *}$ & Decrease $^{* *}$ & Decrease** $^{* *}$ \\
\hline Decrease & F4 & Decrease $^{* * *}$ & Decrease $^{* *}$ & Decrease** $^{* *}$ \\
\hline Decrease & F5 & Decrease & Decrease & Decrease \\
\hline $2000-2011$ & & GDP & Pop & Housing \\
\hline Increase** & F0 & Increase & Increase & Increase \\
\hline Increase** & $\mathrm{Fl}$ & Increase & Increase & Increase \\
\hline Increase*** & F2 & Increase & Increase* & Increase* \\
\hline Increase ${ }^{* *}$ & F3 & Increase & Increase & Increase \\
\hline Increase* & F4 & Increase* & Increase* & Increase* \\
\hline Increase & F5 & Increase & Increase & Increase \\
\hline
\end{tabular}

$* * *=0.01$.

$* *=0.05$.

$*=0.10$.

decline in losses from 1950 to 2011 (statistically significant in two of the three methods) and also a long-term decline in the reported incidence of the most damaging tornadoes over the same period, the reporting issues make it difficult to claim that there has actually been an overall decline in the actual incidence of tornadoes. However, this consistency suggests that there is no apparent secular bias in the damage data, which would be the case if damage showed contradictory trends to incidence and/or intensity.

However, to explore this issue further we have examined linear trends in tornado incidence in the three sub-periods of the dataset identified in the previous section as corresponding to changes in reporting practices. We then compare the trend analysis in damage within those same subperiods. The results can be seen in Table 4 .

The table shows exceedingly strong agreement between trends in reported tornado incidence and normalized damage, with agreement found in 51 of 54 of the possible comparisons. The exceptions have clear explanations: (1) the increase in F3 tornadoes 1950-1973 was one event per year (i.e. very small), and the decrease in losses was minimal and not statistically significant, essentially zero; (2) the decrease in incidence of reported F5 tornadoes 1950-1973 coupled with an increase in normalized GDP losses is likely a function of the larger normalization effects of the GDP methodology; and (3) the increase in F0 tornadoes 1974-1999 is expected and documented as a result of improved reporting (and damage is minimal in any case).

These results give very strong support to the fidelity of the normalization as compared with the reported incidence of tornadoes of differing intensities. The normalized results are also suggestive that the long-term decrease in reported tornado incidence may also have a component related to actual, secular changes in tornado incidence beyond reporting changes. To emphasize, we do not 
Table 5. Normalized damage (housing unit and income adjusted) by state and by tornado incidence.

\begin{tabular}{|c|c|c|c|c|c|}
\hline State & Tornadoes & $\begin{array}{l}\text { Millions house/income } \\
\text { adjustment damage } \\
\text { (in dollars) }\end{array}$ & $\begin{array}{l}\text { Land area } \\
\text { Sq. miles }\end{array}$ & $\begin{array}{l}\text { Damage per } \\
\text { square mile } \\
\text { (in dollars) }\end{array}$ & $\begin{array}{l}\text { Damage per } \\
\text { tornado } \\
\text { (in dollars) }\end{array}$ \\
\hline MA & 156 & 7351 & 7840 & 937,565 & 47.12 \\
\hline $\mathrm{CT}$ & 90 & 1538 & 4845 & 317,351 & 17.08 \\
\hline IN & 1305 & 9336 & 35,867 & 260,307 & 7.15 \\
\hline $\mathrm{AL}$ & 1854 & 9762 & 50,744 & 192,379 & 5.27 \\
\hline GA & 1427 & 8140 & 57,906 & 140,572 & 5.70 \\
\hline MO & 2024 & 9345 & 68,886 & 135,663 & 4.62 \\
\hline $\mathrm{OH}$ & 959 & 5424 & 40,948 & 132,447 & 5.66 \\
\hline MS & 1898 & 6101 & 46,907 & 130,070 & 3.21 \\
\hline OK & 3428 & 8199 & 68,667 & 119,402 & 2.39 \\
\hline IL & 2175 & 6392 & 55,584 & 114,990 & 2.94 \\
\hline IA & 2263 & 5830 & 55,869 & 104,348 & 2.58 \\
\hline MI & 963 & 5921 & 56,804 & 104,234 & 6.15 \\
\hline MN & 1609 & 8217 & 79,610 & 103,216 & 5.11 \\
\hline KS & 3735 & 7919 & 81,815 & 96,791 & 2.12 \\
\hline LA & 1748 & 3663 & 43,562 & 84,094 & 2.10 \\
\hline $\mathrm{TN}$ & 1058 & 2996 & 41,217 & 72,684 & 2.83 \\
\hline PA & 712 & 2829 & 44,817 & 63,114 & 3.97 \\
\hline FL & 3039 & 3362 & 53,927 & 62,344 & 1.11 \\
\hline KY & 772 & 2388 & 39,728 & 60,100 & 3.09 \\
\hline WI & 1263 & 3256 & 54,310 & 59,952 & 2.58 \\
\hline MD & 322 & 507 & 9774 & 51,844 & 1.57 \\
\hline NE & 2592 & 3707 & 76,872 & 48,228 & 1.43 \\
\hline $\mathrm{NC}$ & 1178 & 2320 & 48,711 & 47,634 & 1.97 \\
\hline TX & 7990 & 12,438 & 261,797 & 47,509 & 1.56 \\
\hline $\mathrm{SC}$ & 913 & 1223 & 30,109 & 40,612 & 1.34 \\
\hline AR & 1684 & 4295 & 113,635 & 37,797 & 2.55 \\
\hline NJ & 142 & 265 & 7417 & 35,670 & 1.86 \\
\hline NY & 394 & 1306 & 47,214 & 27,657 & 3.31 \\
\hline VA & 641 & 819 & 39,594 & 20,687 & 1.28 \\
\hline ND & 1415 & 1038 & 68,976 & 15,050 & 0.73 \\
\hline $\mathrm{DE}$ & 58 & 28 & 1954 & 14,563 & 0.49 \\
\hline SD & 1679 & 1003 & 75,885 & 13,217 & 0.60 \\
\hline RI & 11 & 8 & 1045 & 7522 & 0.71 \\
\hline $\mathrm{NH}$ & 85 & 66 & 8968 & 7324 & 0.77 \\
\hline WV & 122 & 154 & 24,078 & 6389 & 1.26 \\
\hline AZ & 225 & 276 & 52,068 & 5297 & 1.23 \\
\hline $\mathrm{CO}$ & 1861 & 502 & 103,718 & 4845 & 0.27 \\
\hline OR & 102 & 306 & 95,997 & 3184 & 3.00 \\
\hline UT & 118 & 258 & 82,144 & 3144 & 2.19 \\
\hline VT & 45 & 28 & 9250 & 3017 & 0.62 \\
\hline WA & 107 & 178 & 66,544 & 2669 & 1.66 \\
\hline ME & 121 & 69 & 30,862 & 2247 & 0.57 \\
\hline CA & 380 & 340 & 155,959 & 2178 & 0.89 \\
\hline MT & 386 & 261 & 145,552 & 1791 & 0.68 \\
\hline WY & 619 & 158 & 97,100 & 1622 & 0.25 \\
\hline NM & 536 & 174 & 121,356 & 1430 & 0.32 \\
\hline ID & 163 & 26 & 82,747 & 318 & 0.16 \\
\hline NV & 70 & 10 & 109,826 & 94 & 0.15 \\
\hline PR & 5 & 0 & 3459 & 55 & 0.04 \\
\hline HI & 12 & 0 & 6423 & 12 & 0.01 \\
\hline AK & 3 & - & 571,951 & - & - \\
\hline
\end{tabular}


Table 6. Distribution of tornado damage through the calendar year.

\begin{tabular}{|c|c|c|c|c|c|c|c|c|}
\hline Month & Tornadoes & $\begin{array}{l}\text { Percent } \\
\text { of total }\end{array}$ & $\begin{array}{l}\text { Millions } \\
\text { damage } \\
\text { current } \\
\text { (in dollars) }\end{array}$ & $\begin{array}{l}\text { Millions } \\
\text { CPI Adj } \\
\text { damage } \\
\text { (in dollars) }\end{array}$ & $\begin{array}{l}\text { Millions } \\
\text { GDP Adj } \\
\text { damage } \\
\text { (in dollars) }\end{array}$ & $\begin{array}{c}\text { Millions } \\
\text { Pop/Inc } \\
\text { Adj } \\
\text { damage } \\
\text { (in dollars) }\end{array}$ & $\begin{array}{l}\text { Millions } \\
\text { house/ Inc } \\
\text { Adj } \\
\text { damage } \\
\text { (in dollars) }\end{array}$ & $\begin{array}{l}\text { Percent } \\
\text { of total }\end{array}$ \\
\hline 1 & 1246 & 2 & 657 & 1352 & 3139 & 2019 & 2340 & 2 \\
\hline 2 & 1522 & 3 & 1565 & 2662 & 5853 & 3941 & 4546 & 3 \\
\hline 3 & 3686 & 7 & 3337 & 7365 & 17,358 & 10,863 & 12,408 & 8 \\
\hline 4 & 8015 & 14 & 15,409 & 27,825 & 60,997 & 39,793 & 45,821 & 31 \\
\hline 5 & 12,394 & 22 & 10,345 & 18,118 & 38,361 & 26,005 & 29,579 & 20 \\
\hline 6 & 11,002 & 19 & 3345 & 9827 & 30,931 & 19,831 & 24,395 & 16 \\
\hline 7 & 6060 & 11 & 2605 & 4999 & 10,921 & 7267 & 8203 & 5 \\
\hline 8 & 3920 & 7 & 1245 & 2785 & 6831 & 4425 & 5140 & 3 \\
\hline 9 & 3004 & 5 & 974 & 1920 & 4095 & 2611 & 2949 & 2 \\
\hline 10 & 2138 & 4 & 1036 & 2405 & 5582 & 3447 & 3941 & 3 \\
\hline 11 & 2224 & 4 & 2033 & 3650 & 7116 & 4958 & 5435 & 4 \\
\hline \multirow[t]{2}{*}{12} & 1246 & 2 & 883 & 2463 & 6774 & 4190 & 4972 & 3 \\
\hline & 56,457 & & 43,435 & 85,371 & 197,956 & 129,350 & 149,729 & \\
\hline
\end{tabular}

reach any conclusion here that stronger that 'suggestive' and recommend that this possibility be subject to further research, which goes beyond the scope of this study.

On climate time scales there is no indication of increasing incidence of tornadoes, and the increases documented over the short (sub-climate) period 2000-2011 are strongly influenced by the large number of events documented in 2011. However, the decreased frequency of high damage events in recent decades as compared with previous decades is a notable feature in the time series and provides strong counter-evidence to claims found in the scientific literature that the atmospheric environment that spawns tornadoes has intensified leading to more intense events on climate time scales (e.g. Trenberth, 2012). Such claims are commonly found in the popular media and also in the insurance/reinsurance sector where they influence public opinion and decision making in business and government. The most recent review by the IPCC found no basis for claiming an increase (or decrease) in tornado incidence or intensity (IPCC, 2012).

The spatial and intra-annual patterns of damage are also worth noting. Table 5 shows the 50 US states in terms of housing unit and income normalized losses from 1950 to 2011 per square mile of land area and per observed tornado. At the top of the table, perhaps contrary to conventional wisdom, are Massachusetts and Connecticut. Oklahoma has about one-eighth the damage per square mile of Massachusetts while the state with the largest aggregate damage, Texas, has about $40 \%$ of the damage per square mile of Oklahoma. In 2010, Massachusetts and Connecticut were the 5th and 6th most densely populated states, while Texas and Oklahoma were 28th and 37th, respectively (U.S. Census Bureau, 2010). While Massachusetts and Connecticut have lower tornado rates than Oklahoma and Texas, the higher population density means that the tornadoes which occur are more likely to hit buildings and produce damage. Damage is a consequence not only of event incidence but also by the size of the potential target that might be hit by the events. At the state level, more than the nation, a significant proportion of damage is the result of a few events. For Massachusetts, about 95\% of total normalized damage from 1950 to 2011 occurred in a single 1953 event.

Table 6 shows the distribution of tornadoes and normalized damage by month. The months of April, May and June are responsible for $55 \%$ of tornado occurrences and $67 \%$ of damage. Within those months May has the most tornadoes, but April has by far the most damage. The least 
damage occurs in January and September, and all months experience damage. By the end of June, more than $80 \%$ of historical normalized damage had occurred.

\section{Conclusions}

The analysis presented in this paper indicates that normalized tornado damage in the US from 1950 to 2011 declined in all three normalization methods applied (two are statistically significant one is not). The degree to which this decrease is the result of an actual decrease in the incidence of strong tornadoes is difficult to assess due to inconsistencies in reporting practices over time. However, an examination of trends within sub-periods of the dataset is suggestive that some part of the long-term decrease in losses may have a component related to actual changes in tornado behaviour. Further research is clearly needed to assess this suggestion.

However, we can definitively state that there is no evidence of increasing normalized tornado damage or incidence on climatic time scales. In this context, the 2011 tornado season stands out as a sharp departure from recent experience, with greater normalized losses than any year since 1974. Until 2011, for whatever the reasons, the United States experienced a remarkable streak of good fortune with respect to tornado impacts as compared to that seen in a longer view.

It is logical that if tornado incidence was to increase in the future, then we should expect to see damage levels to increase as well. However, even in the absence of climatological changes in tornado occurrence, losses will continue to increase if societal change results in increasing wealth and property exposed to tornado events. In this context, debates about the influence of human-caused climate change on increasing tornado occurrence are essentially irrelevant to the policy issues associated with tornadoes as detection of such a signal in tornado occurrence is not currently possible.

In any case, resolving such questions is unnecessary to raise concerns about the need to better prepare for future impacts of tornadoes on life and property. Effective preparation makes sense under any scenario of the future, as tornadoes are a constant threat, with potentially very large impacts on people and their communities.

\section{Notes}

1. The source of information for the following summaries of 1953, 1965, 1974 and 2011 is NOAA.

2. For this test we use the housing unit and income-based normalization as described below.

3. Specifically, for $1950-1996$ the proportion of total damage was: Bin 5: 1.5\%; Bin 6: 8.7\%; Bin 7: 23.1\%; Bin 8: 34.4\%; Bin 9: $32.3 \%$ and for 1996-2011: Bin 5: 1.6\%; Bin 6: 7.8\%; Bin 7: $18.6 \%$, Bin 8: $37.3 \%$; Bin 9: $34.5 \%$.

4. Specifically, for Bin 7 the average losses per tornado differ by less than $2 \%$; Bin 8 has about $10 \%$ less losses per tornado in the more recent period and Bin 9 has about $14 \%$ more. Because there is slightly more total damage in Bin 8 than Bin 9, these differences cancel each other out just about completely when aggregated to a total loss amount. Part of the observed differences in Bins 8 and 9 (in particular) is no doubt due to the very small number events in each of these Bins: for 1950-1996, Bins 7, 8, 9 saw 2,145, 334 and 34 tornadoes respectively, while 1996-2011 saw 401, 92, and 8 respectively.

5. For instance, the SPC losses for 2011 are less than half of those compiled by NOAA/NCDC using a more rigorous methodology, as described below.

6. There are of course, multiple valid ways to calculate a total loss estimate for any disaster, see the Discussion in Pielke and Pielke (1997).

7. Such a scaled normalization could be performed with respect to the lower values found in the SPC database or the higher values tabulated by Munich Re, e.g. Munich Re (2012).

8. The $\$ 150$ billion is based on the 'no mitigation' calculation from Vranes and Pielke (2009).

\section{References}

Boruff, B. J., Easoz, J. A., Jones, S. D., Landry, H. R., Mitchem, J. D., \& Cutter, S. L. (2003). Tornado hazards in the United States. Climate Research, 24, 103-117. 
Bouwer, L. (2011). Have disaster losses increased due to anthropogenic climate change? Bulletin of the American Meteorological Society, 92, 39-46.

Brooks, H. E., \& Doswell, C. A. (2001). Normalized damage from major tornadoes in the United States: 1890-1999. Weather Forecasting, 16, 168-176.

Brooks, H. E., \& Dotzek, N. (2008). The spatial distribution of severe convective storms and an analysis of their secular changes. In H. F. Diaz \& R. J. Murnane (Eds.), Climate extremes and society. Cambridge: Cambridge University Press.

Doswell, C. A., Brooks, H. E., \& Dotzek, N. (2008). On the implementation of the enhanced Fujita scale in the USA. Atmospheric Research, 93, 554-563.

Downton, M. W., Miller, J. Z. B., \& Pielke, Jr., R. A. (2005). Reanalysis of the U.S. national flood loss database. Natural Hazards Review, 6, 13-22.

Downton, M. W., \& Pielke, Jr., R. A. (2005). How accurate are disaster loss data? The case of US flood damage. Natural Hazards, 35(2), 211-228.

Feuerstein, B., Dotzek, N., \& Grieser, J. (2005). Assessing a tornado climatology from global tornado intensity distributions. Journal of Climate, 18, 585-596.

IPCC. (2012). Managing the risks of extreme events and disasters to advance climate change adaptation. A Special Report of Working Groups I and II of the Intergovernmental Panel on Climate Change [Field, C. B., V. Barros, T. F. Stocker, D. Qin, D. J. Dokken, K. L. Ebi, M. D. Mastrandrea, K. J. Mach, G.-K. Plattner, S. K. Allen, M. Tignor, \& P. M. Midgley (eds.)]. Cambridge and New York: Cambridge University Press.

Munich Re. (2012, January 4). 2011 Natural catastrophe year in review. Retrieved from http://www.ctnow. com/media/acrobat/2012-01/67158951.pdf

NOAA. (2011). National Climatic Data Center, State of the climate: Tornadoes for annual 2011. Retrieved April 24, 2012, from http://www.ncdc.noaa.gov/sotc/tornadoes/2011/13

Nordhaus, W. (2010). The economics of hurricanes and implications of global warming. Climate Change Economics, 1(1), 1-20.

Pielke, Jr., R. A. (2008, July 14). Replications of our normalized hurricane damage work. Prometheus. Retrieved from http://cstpr.colorado.edu/prometheus/archives/disasters/001478replications_of_our_. html

Pielke, Jr., R. A., Gratz, J., Landsea, C. W., Collins, D., Saunders, M., \& Musulin, R. (2008). Normalized hurricane damages in the United States: 1900-2005. Natural Hazards Review, 9(1), 29-42.

Pielke, Jr., R. A., \& Pielke, Sr., R. A. (1997). Hurricanes: Their nature and impacts on society. London: John Wiley and Sons.

Simmons, K. M., \& Sutter, D. (2011). Economic and societal impacts of tornadoes. Boston, MA: American Meteorological Society. Retrieved from http://www.spc.noaa.gov/wcm/index.html\#data

Smith, M. (2012). When the sirens were silent. Wichita, KS: Mennonite Press/Mike Smith Enterprises, LLC, $65 \mathrm{pp}$.

Trenberth, K. (2012). Framing the way to relate climate extremes to climate change. Climatic Change, 115, $283-290$.

U.S. Census Bureau. (2010). Census data. Retrieved from http://2010.census.gov/2010census/data

U.S. Department of Commerce. (2011). National economic accounts. Bureau of Economic Analysis. Retrieved from http://www.bea.gov/national/index.htm\#gdp

U.S. Department of Labor. (2011). Consumer price index. Washington, DC: Bureau of Labor Statistics. Retrieved from ftp://ftp.bls.gov/pub/special.requests/cpi/cpiai.txt

Verbout, S. M., Brooks, H. E., Leslie, L. M., \& Schultz, D. M. (2006). Evolution of the U.S. Tornado database: 1954-2003. Weather and Forecasting, 21, 86-93.

Vranes, K., \& Pielke, Jr., R. A. (2009). Normalized earthquake damage and fatalities in the United States: 1900-2005. Natural Hazards Review, 10, 84-101. 